\title{
FOOD, CULTURE, GLOBALIZATION: INFLUENCE ON HEALTH
}

\section{Massimo Vincenzi}

\section{Service of Gastroenterology and Digestive Endoscopy, San Pier Damiano Hospital, Faenza, Italy}

\begin{abstract}
Globalization has negative effects on the health of the individuals and the populations through mechanisms that lead to increased inequalities between and within countries, economic instability and lack of improvements in supply of sanitary services that reflects on the variations of life expectancy at birth. The problem is the globalization doesn't act evenly, it supports those countries and groups of population that already have plenty of resources, and it strucks poorer countries. Globalization favors the rich (people and countries) also thanks to the power they have in establishing rules and in particular business and market rules. Among the fundamental right of people adequate nutrition is a prerequisite to carry out a satisfactory work, social life, reproductive and development factor. An "effective access to a power supply in quantity and quality sufficient for a productive life and health for all individuals" be defined in accordance with the United Nations Food Security is not a right evenly spread throughout the world; in fact, $80 \%$ of the world population does not have the possibility to eat in adequate quantity and have access to safe water sources. In economically disadvantaged countries, population growth, urbanization and internal growth massively increase the demand for food of animal origin. This change in the supply of billions of people has the potential to produce a substantial change in the lives of many poor people living in rural areas. The diet of the whole world is moving towards homogeneity, the diet of Africa and parts of Asia has expanded its menu, adding the globalized foods to the traditional ones. But this is not a good news, because today millions of people more than in the past, try calorie-rich foods, animal protein, sugar, fat. This leads to disastrous consequences, from the point of view of health, as evidenced by the increasing of the so-called welfare diseases linked to excess in highly processed foods and the food and fast food multinationals facilitate and enhance this trend.
\end{abstract}

Key words: globalization, diet, over nutrition, malnutrition.

Globalization, as the emergence and consolidation of a global market, has negative effects on the health of individuals and populations through mechanisms that lead to increased inequalities between and within countries. These are the premises of a report by the WHO Commission on Social Determinants of Health that recommends to reverse this trend, redistributive policies, rules and safeguarding the rights to act on the reorganization of production and the labor market, on trade agreements between countries and the procedures to solve disputes, financial markets and capital mobility, and the foreign debt of medium- and low-income countries [1].

The globalization can act through its effects on health: i) the social and political environment, including health policies; ii) on social stratification and on population movements between the layers; iii) exposure, depending on the social stratum, disease determinants; iv) the different disease susceptibility in different social strata; $v$ ) on the physical and functional characteristics of the health care system.

That's why there are differences in illness and health outcomes, with consequent inequalities and different consequences of the same diseases, which in turn can have an effect on the social stratification.

Globalization could have positive health effects. For example, global policies for the control of infectious diseases, and AIDS in particular, could enable the development and distribution of vaccines and drugs in to encourage the sectors of the population who most need to access to these resources.

The globalization acts negatively on health mostly increasing the inequalities. Considering the Gross Domestic Product (GDP) and adjusting the results based on the size of the countries, economists say that international inequalities have decreased, but this decrease is mainly due to the increase in per capita GDP of China and Indiaì. In addition, the decrease of international inequality has been accompanied by an increase in inequality between countries (for example the stagnation of many African economies) and, above all, inequality within countries.

This dynamic is reflected, as regards health, on changes in life expectancy at birth. The authors argue

\section{Correspondence to:}

Massimo Vincenzi

Service of Gastroenterology and Digestive Endoscopy, San Pier Damiano Hospital, Faenza, Via Portisano 1, 48018 Faenza (RA), Italy.

Tel.: +39.3357047455.

E-mail: massimovincenzi@hotmail.com 
that in the last 25 years, this indicator has lost, compared to the estimated potential with figures for the period between 1960 and 1980, 1.52 years (0.59 in China, 3.57 in the former Soviet Union, 8.95 in sub-Saharan Africa) [2].

This loss is primarily due to the increased income inequality within countries, economic instability and lack of improvements in the delivery of health services. The problem is that globalization does not act uniformly. It favors those countries, and those population groups within countries, which already have abundant resources (raw materials, industry, strong social institutions, human capital), but leaves behind those countries that do not. It strikes the poorest population groups and their countries; favoring the rich, thanks to the power that they have in establishing the rules and in particular rules of the market and work.

The globalization of markets doesn't bring beneficial to health, if the principle that the rule is "the invisible hand of the market". Not even development aid can reverse the trend of increasing inequalities, and therefore the deterioration of health for large sections of the population. Not only because the majority of rich countries give in development aid much less than it could or should give, have repeatedly promised to get to $0.7 \%$ of GDP, in most cases they do not reach $0.4 \%$. But also because these aids are used inefficiently and ineffectively, and certainly not to address the root determinants of health and even to sustainably strengthen health systems, especially since, as the flow of money in development aid is much less general than that ranges from poor countries to rich to repay foreign debt and related interest.

Among the fundamental right of people - work, house, base - adequate nutrition health services - is a prerequisite to carry out a satisfactory work, social life, reproductive and development factor. An "effective access to a power supply in quantity and quality sufficient for a productive life and health for all individuals" be defined in accordance with the United Nations Food Security is not a right evenly spread throughout the world; In fact, $80 \%$ of the world population does not have the possibility to eat in adequate quantity and have access to safe water sources.

The data from the most recent analysis of productions, exchanges and world consumption show that the global revolution in agriculture has deep implications for human health, livelihood and environment.

In economically disadvantaged countries, population growth, urbanization and internal growth massively increase the demand for food of animal origin. This change in the supply of billions of people has the potential to produce a substantial change in the lives of many poor people living in rural areas.

The risk was highlighted in October 2007 by Jacques Diouf, FAO Director-General, who launched a cry of alarm "the food reserves are at the lowest level ever since the 80 's"

Among this negative phenomena there is also a paradox: while the diet of the whole world is moving towards homogeneity, the diet of Africa and parts of Asia has expanded its menu, adding the globalized foods to the traditional ones. But this is not a good news, because today millions of people more than in the past, thanks to the increase in income, urbanization and knowledge (and through advertisements) try calorierich foods, animal protein, sugar, fat, discovered thanks to the internet.

This leads to disastrous consequences, from the point of view of health, as evidenced by the increasing of the so-called welfare diseases linked to excess in highly processed foods. The food and fast food multinationals facilitate and enhance this trend, that in some Western countries (and especially Northern Europe) is declining.

It is therefore necessary to increase public awareness on the importance of having a healthy diet, but also awareness about the source of food.

Having globally more varied diet means not only to have more possibilities to ensure the food to the nine billion people who will populate the earth by 2050 , but also to fight hunger, malnutrition and over-nutrition and together, to protect our food sources from the impact of climate change.

Ultimately, the rapid globalization has resulted in large-scale new influences on human health models. The multiple changes on a global scale, economic, social, demographic, environmental and climate, connecting more and more to the epidemic forms of some chronic diseases, such as cardiovascular and metabolic disorders, but also the emergence and re-emergence of infectious diseases, spread of cigarette smoking and persistence of health disparities.

The primary prevention efforts to reduce the health risks caused by these global influences, pose a unique challenge. First we should be able to have additional resources and strategies to reduce health risks related to over nutrition and malnutrition.

I would conclude with the words of Giovanni Berlinguer: "It's ironic that while globalized finance, information, migration, trade, scientific and technological knowledge, production and human labor, an essential good such as health is neglected or damaged by a globalization so prominent and pervasive. Since globalization is the current stage and future development, and it can answer to many human needs, now health needs to be addressed as a global objective, as an asset for which operate anywhere in explicit and planned way" [3].

\section{REFERENCES}

1. WHO Commission on Social Determinants of Health. Closing the gap in a generation. Health equity through action on the social determinants of health. Geneva: WHO; 2008.

2. University of Ottawa. Globalization and health knowledge network. Towards health-equitable globalisation: rights, regulation and redistribution. Final report to the Commission on Social Determinants of Health. Institute of Population Health, University of Ottawa, 2008

3. Berlinguer G. The global health in the perspective 2004. Report on Health and Globalization. 